\title{
Methodology to Determine Child Labour Rates and Scholastic Retardation in D/Dinajpur
}

\author{
Sankarsan Tokdar ${ }^{1 *}$, Ashoke Das ${ }^{1}$ and Anil Bhuimali ${ }^{2}$ \\ ${ }^{I}$ Department of Mathematics, Raiganj University, Raiganj, India \\ ${ }^{2}$ Vice Chancellor, Raiganj University, Raiganj, India
}

*Corresponding author: gourab29@gmail.com

\begin{abstract}
Form of child labour for many decades is one of Dakshin Dinajpur's greatest problems. Many campaigns against child labour are organized by the Government and NGOs. However, because of the many socioeconomic conditions of Dakshin Dinajpur they were unable to achieve their goal. In order to estimate the number of children's work and situations, a General Survey 2016 (GS16) was conducted privately. In this research area we try to establish a methodology to determine child labour rates and scholastic retardation in Dakshin Dinajpur.
\end{abstract}

Keywords: Child Labour, Scholastic Retardation, GS16

The research work is mainly focused on two unique issues. The first issue is to find out estimate of child labour in Dakshin Dinajpur and the second is to investigate if there is a link between child labour and education. Most of the analysis has been done based on the data produced by GS16 (General Survey 2016). In spite of many limitations, it remains the most important and comprehensive data set that can be used in the estimate the extent of child labour in Dakshin Dinajpur. The research work and the data analysis should be done in such a way that anybody can easily relate with other countries data.

\section{Description of Research Methodology}

Aim of this research is to set up a workable definition of child labour for Dakshin Dinajpur and use of such definition to estimate the extent of child labour. Most of the analysis has been done based on the data provided by GS16. The actual numbers of children engaged in child work and those engaged in child labour are estimated totally based on questioning procedure of GS16. This procedure is also help 
to determine the link between child labour and the educational circumstances of child labour. Specially it also helps to investigate any relationship between child labour and grade specific scholastic retardation. Grade specific retardation rates for different categories of children engaged in Child labour are calculated. These rates are used to investigate the link between child labour and scholastic retardation.

\section{Defining child labour in Dakshin Dinajpur}

Child labour was calculable on the idea of a number of hypotheses for the needs of this analysis. These include numerous cut - off limits in hours that children can try to work without compromising their development or schooling. First, a lower cut off limit of 1 hour per week was imposed in order to be able to determine the number of children who are considered to be working. All children aged 5 - 17, engaged in some kind of activity, whether economic or non - economic, are considered to be engaged in child labour. Secondly, in order to determine who of all children engaged in child labour, is actually engaged in child labour, due to the number of hours worked, the following upper limits were imposed on the number of hours worked.

The cut off limits are shown in the table 1 below:

Table 1: Upper cut offs limits for child work

\begin{tabular}{|c|c|c|c|c|}
\hline \multirow{2}{*}{ Work Status } & \multicolumn{4}{|c|}{ Age Group } \\
\hline & $5-9$ & $10-12$ & $13-14$ & 15- 17 \\
\hline $\begin{array}{l}\text { Economic activity (excluding } \\
\text { subsistence agriculture) }\end{array}$ & $14 \mathrm{hrs}$ per week & $21 \mathrm{hrs}$ per week & $21 \mathrm{hrs}$ per week & $\begin{array}{l}35 \mathrm{hrs} \text { per week in } \\
\text { agriculture, and } 43 \mathrm{hrs} \text { per } \\
\text { week elsewhere }\end{array}$ \\
\hline Subsistence Agriculture & $14 \mathrm{hrs}$ per week & $21 \mathrm{hrs}$ per week & $21 \mathrm{hrs}$ per week & $\begin{array}{l}35 \mathrm{hrs} \text { per week in } \\
\text { agriculture, and } 43 \mathrm{hrs} \mathrm{per} \\
\text { week elsewhere }\end{array}$ \\
\hline $\begin{array}{l}\text { Unpaid domestic work/ } \\
\text { Household chores }\end{array}$ & $14 \mathrm{hrs}$ per week & $21 \mathrm{hrs}$ per week & $28 \mathrm{hrs}$ per week & $\begin{array}{l}35 \mathrm{hrs} \text { per week in } \\
\text { agriculture, and } 43 \mathrm{hrs} \mathrm{per} \\
\text { week elsewhere }\end{array}$ \\
\hline School Work & 5 hrs per week & 5 hrs per week & 5hrs per week & 5 hrs per week \\
\hline
\end{tabular}

Basically, child labour in India as defined in this dissertation will consists of all children under the age of 15 years, who are engaged in all forms of child work, excluding the following categories of children:

$\square$ those who are under 5 years of age;

$\square$ those aged between 5 and 9 years who spend less than 5 hours per week on school work, or less than 14 hours per week for any other labour activities;

$\square$ those aged between 10 and 12 years, who spend less than 5 hours per week on school work, or less than 21 hours per week on all the other labour activities;

$\square$ those aged between 13 and 14 years, who spend less than 5 hours per week on cleaning activities at school, or less than 28 hours per week, if they are engaged in unpaid domestic work, or less than 21 hours per week for any economic activity, including subsistence agriculture; and 
those aged between 15 to 17, who spend less than 5 hours on school cleaning activities, or less than 35 hours if they are working in the agricultural sector, or less than 43 hours if they are engaged in unpaid domestic work, or working in economic activities including subsistence agriculture.

Added to the above, are all children aged 5-17 years, who:

Are engaged in work, which is of a hazardous nature either due to the nature of the industry, occupations, or conditions in which the children work.

Are engaged in the unconditional worst forms of child labour, e.g. commercial prostitution, illicit trade, armed conflict etc.

The above conditions and hypotheses have been reached by reviewing the literature on what other researchers in the same field of study have done on the topic. As it provides the platform for compiling internationally comparable statistics, the relevant international legislation on child labour has been reviewed. The domestic legal system is of the utmost importance as it ensures the implementation of the internationally agreed conventions, through the enactment of laws and their continuous enforcement through relevant regulations.

While the debate on what constitutes child labour may still be far from over, it should be agreed by the end of this chapter that the conceptual framework adopted in this research is the right one. Ideally, Member States have been given some leeway to virtually decide on what constitutes child labour in the country in accordance with their own judgment and the prevailing national legislation.

\section{The Model}

A conceptual framework in the form of a model was developed in order to be able to operationalize the definition used in this research. The model is presented on the next page in Figure 1. A model to use the relevant questions in the GS16 questionnaire needed to estimate child labour and other components of child labour was needed. In the GS16, questions were asked about the working conditions and environment of children, the effects of work on the health and education of a child, the frequency and severity of workrelated injury, the incidence of physical and sexual abuse, and whether children were working for long hours. Responses to all of these and other issues related to working conditions that could compromise the well-being and development of the child were used to estimate the number of children engaged in dangerous work. The questions related to the number of hours spent in carrying out an activity were used to determine the lower and upper cut off limits for child labour, as well as hazardous work in the case of child labour. The model shows how a sequence of operations was performed to determine the number of children involved in child labour, dangerous labour, and ultimately child labour. The $\mathrm{C}++$ programming code was specifically developed to derive all of the model's critical variables and to estimate child labour.

\section{Operationalizing of the model using the GS16 Dataset}

In order to be able to give a meaningful explanation of the methodology followed in this dissertation for estimating child labour, I need to give a brief background on the GS16 dataset at the centre of this research. The GS16 dataset is the electronic record of the 2016 General Survey (GS16) processed results conducted on a probability sample of 18031 households at determining the extent of child labour in Dakshin Dinajpur. In two phases, the survey was conducted. In the first phase, all the 18031 households 
in the national sample were interviewed with the Phasel questionnaire to identify households with at least one child engaged in child labour activities. A subsample of 2345 households identified were then interviewed using the Phase 2 questionnaire during phase 2 of the survey. In the Phase 2 questionnaires, more detailed questions were asked about the activities in these households of all children aged 5 to 17 years. Among the main topics covered in this survey were: the type of activity in which the child was involved; the number of hours a week the child spent on the activity; the child's work environment and working conditions. Other themes covered the D/Dinajpur Children's profile in terms of demographics, living conditions, whether they attend school and family structure in the households they live in. Some of the variables in the published GS16 data set were based on the analysis for this dissertation. The variables are derived from the answers to the GS16 questionnaire on issues such as the activities of children, the hours they worked, the highest level of education they had achieved, and whether they attended school at the time, etc. The GS16 questionnaire did not ask any questions about the current school-going children's enrolment grades. Consequently, their enrolment grades were imputed from the reported highest level of education achieved for those children who attended school. The report discusses various limitations of the GS16 dataset.

\section{Estimation of working Children}

If children fulfilled certain criteria, they were classified as working. The criteria used here are that children must be aged 5 to 17 years to be counted as working and must have been engaged in some kind of work activity (economic or non - economic) for at least 1 hour per week. In essence, the cut-off of at least 1 hour per week to determine whether a child works is consistent with the UN recommendation of at least 1 hour per week used to determine economic activity in labour statistics. This is not practical for child labour, especially in a developing country where children have to help in nearly every activity to which members of their family are attached. Some child labour, while some are not, is economic in nature. Again, some of the children's work is not considered economic activity using the UN recommendation to define economic activity.

However, in the situation in India, some of the work, which is not considered as economic activity internationally, can be a serious source of child labour. The unpaid domestic work performed by children is noteworthy. In previous research, it has been suggested that if a child is in a household where he or she does not have a parent, grandparent or family member, then child labour would most likely occur. There was no evidence to support this viewpoint. Indeed, many children live in households where they have no parent, grandparent or family member and are not engaged in child labour. For the across Dakshin Dinajpur during November 2016. The survey was aimed of wood and water for domestic purposes will be assumed and therefore considered as unpaid domestic work, unless there is evidence of work being carried out in a business environment or in the case of employment. Also, subsistence agriculture will be treated separately when it can be identified for the purposes of this research, but in general as part of economic activity.

Consequently, the following categories of child work have emerged:

(a) Economic activity (excluding subsistence agriculture)

(b) Subsistence agriculture

(c) Unpaid domestic work/Household chores 
(d) School Cleaning work

(e) No labour activity

The first two categories (a) and (b) above are children involved in economic activities. Categories (c) and (d) are children engaged in non-economic child labour. Again, when discussing child work, it was considered unreasonable to bundle children together in their usual demographic age categories. It is expected that a child aged 14 will perform at a much higher level in child labour than a 10 -year-old. For the analysis, age categories 5-9, 10-12, 13-14 and 15-17 were used. Lastly, in line with ILO recommendations, it was decided to impose a1-hour reduced cut off per week for any child's involvement in an activity to be counted as child labour. Due to hours of engagement and the age of the child, some specific longhour cut-offs were also imposed for child labour to be counted as child labour. A maximum cut-off of 43 hours was preferred over the 45 -hour weekly cut-off to facilitate international comparison, particularly with regard to the ILO's recent work.

\section{Estimation of children in hazardous work}

Ideally, it would be necessary to consider each child's economic activity against a list of economic activities, industry sections, and specific occupations that were declared hazardous by government after thorough stakeholder consultation. As of now, no such list has been gazetted by government; and even if there is one that would need to be coded at the appropriate level of detail during data processing for such a list to be applicable to the GS16 data set. Since (1) there is no evidence to suggest that the GS16 data set can provide these variables at the appropriate level of detail, and (2) in many cases, the variables of industry and occupation are not specified; it is not possible to classify child labour activities on the basis of industry and occupation into hazardous and non-hazardous. The following items (a) to (g) show how the GS16 questionnaires used answers to various questions to estimate the number of children engaged in hazardous work.

\section{(a) Sexual harassment or abuse}

Children who are subjected to sexual harassment or abuse by fellow workers, the employer or family members of the employer purposes of this research, it was decided that the fetching clearly experience dangerous working conditions. The number of children in this category was estimated as all children who:

1. stated in questionnaire that they experienced some kind of sexual harassment or abuse through unwanted sexual remarks / suggestions / gestures or unwanted sexual touch or rape; and

2. stated in questionnaire that the perpetrators were employer's fellow workers, employer or family/ friends.

\section{(b) Work detrimental to school}

The combination of questions indicates directly whether the activities of children are detrimental to their education. Children were classified as having child labour activities that are detrimental to their schooling if:

1. In questionnaire they indicated that they had missed school for more than 5 days in the last 12 months (this is equivalent to missing at least one full week of schooling); and 
2. In questionnaire they indicated that the main reason they had missed school was because they had not attended school.

\section{(c) Injury at work}

Questions were used in conjunction with a minimum of two injuries. Two injuries limit is intended to rule out accidental injury that could occur at any time to any person. Thus, the estimate of children considered to be engaged in hazardous labour-related activities due to a high risk of injury at work was defined as all children who:

1. Answered that they had sustained 2 or more work-related injuries over the past 12 months; and

2. Because of those injuries, children stayed in bed or at home for one day or more, or had sought medical attention of any kind, or had pain for them.

\section{(d) Children's health threatened}

In question children were asked if the disease they had experienced was caused by the labour-related activities they were engaged in. And, in questionnaire, children are asked whether these activities have made the disease worse. Every child who answered' Yes' to either of these two questions was involved in life-threatening work. Either one of these two questions are enough in its own right to spell "hazard."

\section{(e) Doing heavy physical work}

The answer to question was used to determine the number of children at risk of stunted growth, muscle or body injury or even fractured limbs due to heavy physical load carrying. For children under the age of 15 years, carrying heavy loads is not an appropriate activity. Even children aged 15 to 17 years should be considered harmful as these are still years of rapid body growth. Growth of the children could be stunted if they are made more often than rarely to carry heavy physical loads. As a result of Questions, children were classified as engaged in hazardous labour-related activities if they answered:

1. They had to do heavy physical work often or regularly or sometimes; or

2. They rarely had to do heavy physical work and they were under 15 years of age.

\section{(f) Bad working conditions}

Questionnaire was used to determine which of the activities of the children may fall under the hazardous category due to bad or inappropriate working conditions. Children working before sunrise or after sunset were considered; or if there is bad lighting in the workplace; or the child works with dangerous or toxic substances, or works with or close to dangerous machinery or tools; or the child works close to dangerous animals, or works under the fear that somebody might hurt them. Unfortunately, the answers to some of sub-questions could not be used as more information such as industry and occupation would be required to determine whether the risk is real. For example, if a child replied that' Yes, the work was very tiring,' that is not enough in itself for us to decide and whether the working conditions are bad. Similarly, responses such as:' working environment is too hot," working environment is too cold,' and' very noisy work' are all not enough on their own to allow us to make a judgment. Sub-questions (b)working long hours, (c) -working before sunrise or after sunset, and I-working with hazardous or toxic substances are specifically referred to in Sect-oral Determination 8 for farm workers-Child Labour Basic 
Guide, which facilitates the decision in that case. If kids reported that they feared they might be hurt by a person, they were also included among those experiencing poor working conditions. Thus, all children who answered' yes' for (b), (c), I and (l) were counted as children with poor working conditions. On the other hand, when one tries to match the answers to (b) of this question with the number of hours given in question, there are glaring contradictions that cast serious doubts on the reliability of the answers. For instance, you wouldn't expect someone who reported working in question for 72 hours a week to say' No' -they didn't work for long hours, under question. In these circumstances, I decided to rule on the number of hours given in questions.

\section{(g) Working long hours}

Question outlines the number of hours a child has been engaged in activities identified in question; Question outlines the number of hours a child spends in water collection, firewood collection, and other housekeeping activities; and some questionnaire outlines the number of hours spent by a child going to school, in school cleaning, and in school improvement. In comparison with a selected upper cut-off limit, the total number of hours a child spent on all the activities in which he/she was engaged was used to determine becomes the worst form of child labour in urgent need of elimination. The estimation of child labour for this group must be based on guidelines provided by various Sectoral Determinations on specific industries and occupations as provided by the Labour Ministry and cited in the review of the literature. In recent publications (ILO, 2002) -Every child count, consideration has also been given to the current international best practices as provided by the methodology. Consequently, all children aged 15 to 17 years, engaged in economic activity, subsistence farming or household chores for more than 43 hours a week, engaged in commercial farming for more than 35 hours a week, or engaged in school cleaning for more than 5 hours a week, are all counted as engaged in child labour. If children aged 5-17 who engage in economic activity survive the tests provided in the model for hazardous work, they are economically active but not in child labour. All hours spent for labour activities shall be added up to the sum of the total amount of acceptable maximum number of hours in all circumstances during the actual process of estimation.

\section{Derived variables}

Some derived variables had to be established in order to facilitate the estimation process using the $\mathrm{C}++$ programming language. These variables are based on the model and therefore not included in the GS16 dataset published by Statistics SA. At the end of the report, an Annexure provides the $\mathrm{C}++$ code developed for the derivation of variables and estimates of child labour.

\section{Wstatus -Type of labour activity}

Code 1: Economic activity (excluding Subsistence agriculture)

Code 2: Subsistence agriculture

Code 3: Household chores

Code 4: School cleaning work

Code 5: No child work activities

Code 6: Unspecified 


\section{Status 1}

Code 1: Engaged in economic activity (includes $w$ status $=1$ or 2 )

Code 2: Engaged in non-economic activities (includes $w$ status $=3$ or 4 )

Code 3: Not engaged in labour activities

Code 4: Unspecified

\section{Childwk - Different kinds of child labour}

Code 1: Hazardous work

Code 2: Child labour by children aged 5-9 (due to hour cut-offs)

Code 3: Child labour by children aged 10-12 (due to hour cut-offs)

Code 4: Child labour by children aged 13-14 (due to hour cut-offs)

Code 5: Child labour by children aged 15-17 (due to hour cut-offs)

Code 6: Children engaged in child work by not in child labour.

If the grade he / she is enrolled in is below the grade normally expected for his / her age (Shryock, Siegel and Stockwell, 1976:180-181), a child is scholastically retarded. In Dakshin Dinajpur, a child in grade 1 is expected to be 6 or 7 years old. Therefore, Grades 1 and 2 would be the expected grades of enrolment for a 7-year-old.

Similarly, the ages of children enrolled in grades 1 and 2 are expected to be 6-7 years and 7-8 years respectively for Dakshin Dinajpur. Similarly, grade-specific retardation rates were calculated to indicate the rate at which the age of children enrolled in a particular grade is higher than the age for that grade normally expected. Accordingly:

Grade specific scholastic retardation rate is:

$$
\operatorname{gsSRR}_{j}=\left(\frac{\sum_{i=l+2}^{n} x_{i j}}{\sum_{i=1}^{n} x_{i j}}\right) * 100
$$

where,

$\square l$ is a age lying between 1 and $m$ is determined by the age at which children are expected to start schooling

$\square l$ and $l+1$ are the expected grades of enrolment for children aged years.

$\square n$ is the total number of grades over which the retardation rate is being calculated

$\square x_{i j}$ is the actual number of children aged $i$ years who are enrolled in grade $j$.

For boys and girls and all children found in households with child labour characteristics, the age-specific and grade-specific scholastic retardation rates were calculated (phase 2 of the GS16). It was decided to do this split in order to see if there are any gender-specific differences in scholastic retardation and see how these differences can be related to child labour. The following chapter provides graphical representations 
of the results, where the results are discussed. Detailed tables showing scholastic retardation rates calculation for different groups of children with varying child labour characteristics are shown in Annex. I am aware of data quality issues, particularly with regard to the information reported during the survey on the highest level of education achieved, but I believe that the data is sufficiently good to determine the trends required.

\section{Effects of child labour on Educational Progression}

The effects of child labour on the progression of education are investigated by graphical data interrogation. Nine different categories of children were selected that are expected to exhibit different levels of child labour incidence. At the time of the survey, children in each of the 9 categories must have attended school. The categories do not necessarily have the same size, nor do they exclude each other. For each of these groups, grade-specific rates of scholastic retardation and acceleration are calculated and the results are tabulated and plotted. However, it is important to note that imputation of the current enrolment grade. The quality of information at the highest level of educational achievement is of particular importance here.

\section{Estimation of child labour}

Child labour, whether economic or non-economic, has been estimated from children aged 5-17 who are engaged in some kind of child labour. Estimating children engaged in child labour first involves estimating children in hazardous industries or occupations. To this we add the total number of children who are considered child labour in terms of international conventions and domestic legislation, either by their age and/or by the number of hours of engagement in their activities. The extent of child labour in the country will remain somewhat underestimated in the absence of information about the worst forms of child labour, which was not captured by the GS16.

\section{(a) Estimation of Child labour among children aged 5-14 years}

Employing a child under the age of 15 is fundamentally illegal for anyone, unless they have applied and have been granted permission to do so. Even then, there are specific conditions to be observed in the permit. The children aged 5-14 were divided into three age groups, namely 5-9, 10-12 and 13-14, for the purposes of this research. The specific upper limits set out in Table 2 above were applied to the relevant age groups in order to identify any children engaged in work that would normally be expected to be either inappropriate or detrimental to their development and well-being.

Accordingly: All children between the ages of 5 and 9 are engaged in economic activity, subsistence farming or household chores for more than 14 hours per week, or are engaged in school cleaning work for more than 5 hours per week.

All children between the ages of 10 and 12 are engaged in economic activity, subsistence farming or household chores for more than 21 hours per week, or are engaged in school cleaning work for more than 5 hours per week.

According to this definition, all children between the ages of 13 and 14 are engaged in economic activity, subsistence farming for more than 21 hours per week, or are engaged in household chores for more than 28 hours per week, or are engaged in school cleaning work for more than 5 hours per week. 


\section{(b) Estimation of Child labour among children aged 15-17 years}

All children aged 15 or older are permitted to work by law. Therefore, work performed by such children is not child labour, unless it is, of course, dangerous either by nature or by condition. If children between the ages of 15 and 17 are engaged in dangerous work, their work

\section{Childlab}

Code 1: Engaged in child labour (when childwk=1 to 5)

Code 2: Engaged in harmless child work

Hours: The variable hours in the total number of hours a child spends on child work activities in a week.

\section{Estimation of Scholastic Retardation}

In the analysis of educational data, two measures of scholastic progression were used: the grade-specific rate of scholastic retardation and the age-specific rate of scholastic retardation. Calculating the rates of scholastic retardation requires that we have data for all children under study on the grade of enrolment of all children. Children in the GS16 were asked no questions about enrolment. However, enrolment grades can be imputed from the correct mix of the correct questions. Although the GS16 data set does not have information on enrolment grades for children, enrolment grades were imputed for the purposes of this research by a logical combination of two GS16 questions; one from phase 1 and the other from the GS16 Phase 2 questionnaires. In the first questionnaire asks for a child to complete the highest level of education. In the second questionnaire asks if the child is going to school at the moment. If a child who attended school at the time of the survey stated that he / she had completed the highest level of education was grade $\mathrm{G}$, then the imputed current grade of enrolment becomes $\mathrm{G}+1$.

For all children aged 5-17 years, age-specific scholastic retardation rates were calculated from households visited during the second phase of the survey for each single age. It is important to note that these were only a sub-sample of households identified during the first phase of the survey as having child labour characteristics.

Suppose are the number of children of age, enrolled in grade, and suppose children of ageare normally be expected to be enrolled in grades or, then the age-specific scholastic retardation rate for age is given by: Age-specific scholastic retardation rate is:

$$
\operatorname{asSRR}_{i}=\left(\frac{\sum_{j=1}^{k-1} x_{i j}}{\sum_{j=1}^{m} x_{i j}}\right) * 100
$$

where,

$\square k$ is a grade lying between 1 and $m$ is determined by the age at which children are expected to start schooling

$\square k$ and $k+1$ are the expected grades of enrolment for children aged $i$ years.

$\square m$ is the total number of grades over which the retardation rate is being calculated 
$x_{i j}$ is the actual number of children aged $i$ years who are enrolled in grade $j$.

The following are the selected group of children used in the analysis:

$\square$ Group 1: All children in phase 2, who are not engaged in child labour

$\square$ Group 2: All children in phase 2, whether in child labour or not

$\square$ Group 3: All children in phase 2, who are engaged in child labour

$\square$ Group 4: All boys in phase 2, who are not engaged in child labour

$\square$ Group 5: All boys in phase 2, whether in child labour or not

$\square$ Group 6: All boys in phase 2, who are engaged in child labour

$\square$ Group 7: All girls in phase 2, who are not engaged in child labour

$\square$ Group 8: All girls in phase 2, whether in child labour or not

$\square$ Group 9: All girls in phase 2, who are engaged in child labour

\section{CONCLUSION}

The methodology outlined in the model presents an objective approach, at least quantitatively, to estimate child labour from the GS16 data set. However, there are many qualitative issues that determine how child labour is defined today. To arrive at the overall picture of child labour in the district, qualitative approaches must be used to complement the quantitative research, of which GS16 is part. This is particularly true for the worst forms of child labour that are targeted for immediate elimination, such as child exploitation through child prostitution, child use in armed conflict, and child use in illicit trafficking, such as drug trafficking. In India, the extent to which such phenomena exist may determine how far this model will be from the mark. For precisely this reason, estimated child labour from this model may underestimate the actual picture. Although the model makes a good attempt to define what constitutes hazardous working conditions and/or working environment, other researchers may prefer to approach the issue of hazardous work rather differently from the questions available in the GS16. The model estimates hazardous work with no limit to minimum engagement hours.

It is therefore possible to find a child who is classified as being engaged in child labour, who does not meet the minimum conditions of child labour, i.e. 1 hour per week. Dangerous work is dangerous to the life, learning and development of the child; often it doesn't matter how long or how short the engagement period can be. Estimating' light work' was not necessary because it was believed that the long hours cut-offs take the concept of' light work' into account. The quality of the results on the progression of education will depend largely on the quality of the data given on the questions used in the whether there is a case of conditional worst form of child labour in relation to the total number of hours worked. As set out in Sectoral Determination 8 for farm workers, the Basic Guide to Child Labour for Children Working in Agriculture sets an upper cut-off limit of 35 hours per week. This has been incorporated into the equation whenever agriculture is the activity under consideration. 


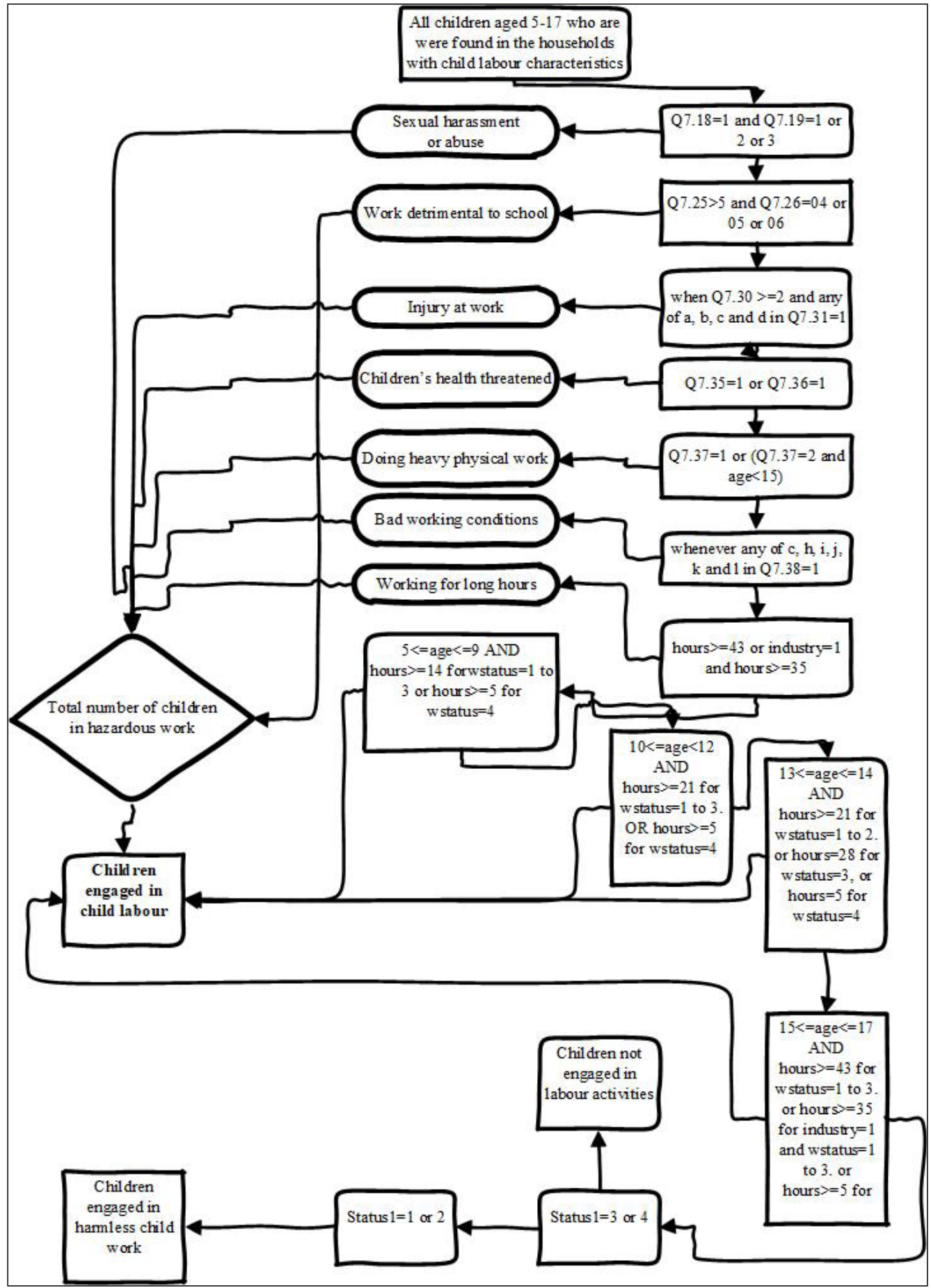

Fig. 1: Conceptual framework of estimating child labour from the GS16 


\section{Logical $\mathrm{C}++$ Code for creating the variable wstatus}

int main (int $\left.\operatorname{argc}, \mathrm{char}^{* *} \operatorname{argv}\right)\{$

int wstatus $=6$;

int q71aownb,q71bunpa,q71cfarm,q71 dcatc,q71epaid,q71fbeg;

int q721ahou,q722afet,q722bhou,q722ccle,q72maina;

int hours91,q91 chour,q96hours, hours;

if $((\mathrm{q} 71$ aownb==1 |q71 bunpa==1\|q71 $\mathrm{cfarm}==1\|\mathrm{q} 71 \mathrm{dcatc}==1\| \mathrm{q} 71$ epaid $==1 \| \mathrm{q} 71 \mathrm{fbeg}==1) \& \&$ q721ahou $>=1)$

wstatus $=1$;

if $($ wstatus $==1)\{$

if $(\mathrm{q} 72 \mathrm{maina}==3)$

wstatus $=2$;

;

if (wstatus! $=1 \& \&$ wstatus! $=2)\{$

if (((q71aownb! =1||q71bunpa! =1\|q71 cfarm! =1\|q71dcatc! =1\|q71epaid! =1\|q71fbeg! =1) \&\& (q722afet $==1 \& \&($ hours $>=1)))$

|| ((q71aownb! =1||q71bunpa! =1||q71 cfarm! =1\|q71dcatc! =1\|q71 epaid! =1\|q71 fbeg! =1) \&\& $(\mathrm{q} 722 \mathrm{bhou}==1 \& \&(\mathrm{q} 91$ chour $>=1))))$

wstatus $=3$;

\}

if (wstatus! $=1 \& \&$ wstatus! $=2 \& \&$ wstatus! $=3$ ) \{

if ((q71aownb! =1\|q71bunpa! =1\|q71 cfarm! =1\|q71dcatc! =1\|q71epaid! =1\|q71 fbeg! =1) \&\& $(\mathrm{q} 722 \mathrm{ccle}==1 \& \&(\mathrm{q} 96$ hours $>=1)))$

wstatus $=4$;

\}

if (wstatus! $=1 \& \&$ wstatus! $=2 \& \&$ wstatus! $=3 \& \&$ wstatus! $=4)\{$

if $(((\mathrm{q} 71 \mathrm{aownb}==2 \& \& \mathrm{q} 71 \mathrm{bunpa}==2 \& \& \mathrm{q} 71 \mathrm{cfarm}==2 \quad \& \& \mathrm{q} 71 \mathrm{dcatc}==2 \quad \& \& \mathrm{q} 71 \mathrm{epaid}==2 \& \&$ $\mathrm{q} 71 \mathrm{fbeg}==2 \& \& \mathrm{q} 722 \mathrm{afet}==2 \& \& \mathrm{q} 722 \mathrm{bhou}==2 \& \& \mathrm{q} 722 \mathrm{ccle}==2) \& \&$ wstatus $==6)$

|| ((q71aownb==1 || q71bunpa==1 || q71 cfarm==1 || q71dcatc==1 || q71epaid==1 || q71fbeg==1 $\mid$ $\mathrm{q} 721$ ahou $<3) \& \&$ wstatus $==6$ )

|| (q71aownb! =1||q71bunpa! =1||q71cfarm! =1\|q71dcatc! =1 ||q71epaid! =1\|q71fbeg! =1)

$\& \&((\mathrm{q} 722 \mathrm{afet}==1 \& \&$ hours $91<1)\|(\mathrm{q} 722 \mathrm{bhou}==1 \& \& \mathrm{q} 91 \mathrm{chour}<1)\|(\mathrm{q} 722 \mathrm{ccle}==1 \& \&$ q96hours $<1$ ) $\& \&$ wstatus $==6)$ )

wstatus $=5$;

\} 
getchar ();

return 0 ;

\}

\section{Logical C++ Code for estimating child labour}

int main (int $\left.\operatorname{argc}, c^{*}{ }^{*} * \operatorname{argv}\right)\{$

int status $1=4$;

string q721ahous;

int wstatus, q13age, agegrp1, agegrp2;

int q71aownb, q71bunpa, q71cfarm, q71dcatc, q71epaid, q71fbeg;

int q721ahou, q722afet, q722bhou, q722ccle, q72maina;

int q718asex, q719abus, q718bsex, q718crap, sexabuse,schatten,injury, healthco,indus;

int q725days, q726rsns,q730noti,q731asta,q731bsee,q731 chav,q731ddis,q735illn,q736actw;

int badcondi,q737phys,q738csun,q738hbad,q738idan,q738jdan,q738kdan,q7381fea;

int hours91,longhour,hours, heavypwk,childlab,childwk;

if $($ wstatus $==1 \|$ wstatus $==2)$

status $1=1$;

else if $($ wstatus $==3 \|$ wstatus $==4)$

status $1=2$;

else if (wstatus $==5$ )

status $1=3$;

if (q13age $>=5 \& \&$ q13age $<=9$ )

agegrp $1=1$;

else if (q13age $>=10 \& \&$ q13age $<=14$ )

agegrp $1=2$;

else if (q13age $>=14 \& \&$ q13age $<=17$ )

agegrp $1=3$;

if (q13age $>=5 \& \&$ q13age $<=9)$

agegrp $2=1$;

else if (q13age $>=10 \& \&$ q13age $<=12$ )

agegrp $2=2$;

else if (q13age $>=13 \& \&$ q13age $<=14$ )

agegrp $2=3$;

else if (q13age $>=14 \& \&$ q13age $<=17$ ) 
agegrp2=4;

if(q721ahous=="@@@"|q721ahous=="***”)

q721ahou $=0$;

sexabuse $=2$;

if $((\mathrm{q} 718 \mathrm{asex}==1 \& \& \mathrm{q} 719 \mathrm{abus}==1)\|(\mathrm{q} 718 \mathrm{asex}==1 \& \& \mathrm{q} 719 \mathrm{abus}==2)\|(\mathrm{q} 718 \mathrm{asex}==1 \& \&$ q719abus==3) $\|$

$(q 718 b \operatorname{bsex}==1 \& \&$ q719abus $==1) \|(q 718 b s e x==1 \& \&$ q719abus==2) $\|(q 718 b \operatorname{bex}==1 \& \&$ q719abus==3) $\|$

$(\mathrm{q} 718 \mathrm{crap}==1 \& \&$ q719abus==1) $\|(\mathrm{q} 718 \mathrm{crap}==1 \& \&$ q719abus==2) $\|(\mathrm{q} 718 \mathrm{crap}==1 \& \&$ q719abus==3))

sexabuse $=1$;

if $($ sexabuse $==2)\{$

schatten $=2$;

if $((\mathrm{q} 725$ days $>5 \& \&$ q726rsns $==4) \|(\mathrm{q} 725$ days $>5 \& \& \mathrm{q} 726 \mathrm{rsns}==5) \|(\mathrm{q} 725$ days $>5 \& \&$

q726rsns==6))

schatten $=1$

\}

if $($ sexabuse $==2 \|$ schatten $==2$ )

injury $=2$;

if $((\mathrm{q} 730$ noti $>1 \& \& \mathrm{q} 731$ asta $==1) \|(\mathrm{q} 730$ noti $>1 \& \& \mathrm{q} 731 \mathrm{bsee}==1) \|$

(q730noti $>1 \& \&$ q731chav==1) $\|($ q730noti $>1 \& \&$ q731ddis==1))

injury $=1$;

if $($ sexabuse $==2||$ schatten $==2 \mid$ injury $==2$ )

healthco $=2$;

if (q735illn==1 \&\& q736actw==1)

healthco $=1$;

if $($ sexabuse $==2||$ schatten $=2||$ injury $==2||$ healthco $==2$ )

heavypwk $=2$;

if $(\mathrm{q} 737 \mathrm{phys}==1|| \mathrm{q} 737 \mathrm{phys}==2 \mid(\mathrm{q} 737 \mathrm{phys}==3 \& \&$ agegrp $2<4))$

heavypwk $=1$;

if $($ sexabuse $==2||$ schatten $==2||$ injury $==2 \mid$ healthco $==2||$ heavypwk $==2)$

badcondi $==2$;

if $(\mathrm{q} 738 \mathrm{csun}==1\|\mathrm{q} 738 \mathrm{hbad}==1\| \mathrm{q} 738 \mathrm{idan}==1\|\mathrm{q} 738 \mathrm{jdan}==1\| \mathrm{q} 738 \mathrm{kdan}==1 \| \mathrm{q} 7381$ fea $==1)$

badcondi $==1$;

if $($ sexabuse $==2 \mid$ |schatten $==2 \mid$ injury $==2 \mid$ healthco $==2 \mid$ |heavypwk $==2 \& \&$ badcondi $==2$ ) 
longhour $=2$;

if $($ hours $>=43 \|($ hours $>=35 \& \&$ indus $==1$ and wstatus $==1))$

longhour $=1$;

childwk=6;

if $($ sexabuse $==1 \|$ schatten $==1 \|$ injury $==1||$ healtheo $==1 \|$

heavypwk $==1 \mid$ badcondi $==1 \|$ longhour $==1$ )

childwk=1;

if (childwk!=1) \{

if $($ agegrp $2==1 \& \&($ hours $>=14 \& \&($ wstatus $==1||$ wstatus $==2 \|$ wstatus $==3)) \|$

(agegrp $2==1 \& \&$ hours $>=5 \& \&$ wstatus $==4)$ )

childwk=2;

\}

if (childwk!=1 \&\& childwk!=2) \{

if $($ agegrp $2==2 \& \&($ hours $>=21 \& \&($ wstatus $==1 \|$ wstatus $==2 \|$ wstatus $==3)) \|$

(agegrp $2==2 \& \&$ hours $>=5 \& \&$ wstatus $==4)$ )

childwk=3;

\}

if (childwk!=1 \&\& childwk!=2 \&\& childwk!=3)\{

if $($ agegrp $2==3 \& \&($ hours $>=21 \& \&($ wstatus $==1 \|$ wstatus $==2)) \|$

(agegrp $2==3 \& \&$ hours $>=28 \& \&$ wstatus $==3) \|$

(agegrp $2==3 \& \&$ hours $>=5 \& \&$ wstatus $==4)$ )

childwk=4;

\}

if (childwk! $=1 \& \&$ childwk! $=2 \& \&$ childwk!=3 \&\& childwk!=4) \{

if $($ agegrp $2==4 \& \&($ hours $>=43 \& \&($ wstatus $==1||$ wstatus $==2||$ wstatus $==3)) \|$

(agegrp $2==4 \& \&$ indus $==1 \& \&$ hours $>=35 \& \&($ wstatus $==1||$ wstatus $==2 \|$ wstatus $==3))$

(agegrp $2==4 \& \&$ hours $>=5 \& \&$ wstatus $==4)$ )

childwk=5;

\}

if $($ childwk $==1 \|$ childwk $==2 \|$ childwk $==3 \|$ childwk $==4 \| \operatorname{childwk}==5)$

childlab=1;

else

childlab $=2$; 
getchar ();

return 0 ;

\}

\section{REFERENCES}

1. Bhalotra S., 2003; Child Labour in Africa: OECD Social, Employment and Migration Working Paper No. 4

2. Budlender, D. \& Bosch, D. 2002. Country report on Child Domestic Workers in South Africa: As part of the programme investigating the Worst Forms of Child Labour, IPEC-SIMPOC: Prepared for the International Labour Organization, IPEC.

3. Heady, C. 2000. "What is the Effect of Child Labour on Learning Achievement? Evidence from Ghana". Innocenti Working Paper No.79. Florence: UNICEF Innocenti Research Centre.

4. ILO, 1973. ILO Minimum Age Convention, 1973 (No 138) Appendix 1: International Conventions on Child Labour, as cited in ILO, pp. 272-275.

5. ILO, 2000. International Programme on the Elimination of Child Labour: IPEC pp.2: http://www.ilo.org/ public/english/standards/ipec/simpoc/simpoc00/page1.htm

6. ILO. 2002. Every child count; New global estimates on child labour: International Programme on the Elimination of Child Labour (IPEC); Statistical Information and Monitoring Programme on Child Labour (SIMPOC): GENEVA; International Labour Office.

7. ILO, 2004. Child labour. A textbook for University students: International Programme on the Elimination of Child Labour (IPEC): GENEVA: International Labour Office.

8. IPEC, 1995. Governing Body Document on Child Labour; Committee on Employment and Social Policy: $264^{\text {th }}$ Session, November 1995. IPEC: Publications and Documents.

9. Nkurlu, J.I. 2000. Child Labour: Background paper - Africa Newsletter 2/2000: http://www.occuphealth. fi/e/info/anl/200/background03.htm

10. O'Donnell O., Van Doorslaer, E. and Rosati, F. 2002. Child Labour and Health: Evidence and Research Issues - Understanding children's work: An inter-Agency Research Cooperation Project of the ILO, UNICEF and World Bank Group.

11. Shryock, Henry, S., Siegel, Jacob B. and Stockwell, Edward G. (Ed), 1976. The methods and Materials of Demography; Condensed edition: San Diego, California: ACADEMIC PRESS, INC.

12. Siddiqi, F. and Patrinos, H.A. 2000. Child labour: Issues, causes and interventions.

13. Sinha, S. 1996. Child Labour and Education Policy in India, 1996: http:/www/ashanet.org/library/articles/ mvf.199607.html

14. India Government Census Report, 2011. 
15. Statistics S.A. 2000. Child Labour in South Africa, A Country Report: Survey of Activities of Young People 1999. PRETORIA: Statistics South Africa, 2000: [Report No. 02-02-02(200)].

16. Statistics S.A. 2000. Child Labour in South Africa, A Summary Report: Survey of Activities of Young People 1999. PRETORIA: Statistics South Africa, 2000: [Report No. 02-02-03(200)].

17. Statistics, S.A. 1999. Survey of Activities of Young People 1999 - First phase questionnaire: PRETORIA: Statistics South Africa, 1999: Social Statistics Division.

18. Statistics, S.A. 1999. Survey of Activities of Young People 1999 - Second phase questionnaire: PRETORIA: Statistics South Africa, 1999: Social Statistics Division.

19. S. A Department of Education, 1996. South African Schools Act, 1996 (Act No. 84 of 1996): http:www. acts.co.za/ed_sasa/

20. S.A Department of Labour, 1997. Basic Conditions of Employment Act, No.75.

21. S.A DoL, 2000. Sectoral Determination for farm workers - Basic guide to child labour (farm workers).

22. S.A Government Gazette, No.17678, 1996. Constitution of the Republic of South Africa. Act 108, 1996.

23. UNESCO, 2002. Education for all - IS THE WORLD ON TRACK? EFA Global Monitoring Report, 2002. UNESCO Publishing.

24. U.S. Department of Labour, 1995. By the sweat and toil of children. Volume II. The Use of Child Labour in U.S. Agricultural Imports \& Forced and Bonded Child Labour. A Report to the Committee on Appropriations U.S. Congress.

25. U.S. Department of Labour, 2002. Advancing the campaign against child labour: Efforts at the country level. US Department of Labour: Bureau of International Labour Affairs, 2002, Washington DC.

26. U.S. Department of Labour, 2002. The Department of Labour's 2001 Findings on the Worst Forms of Child Labour: Trade and Development Act: US Department of Labour; Bureau of International Labour Affairs: 2002, Washington DC.

27. U.S. Department of Labour, 2000. By the sweat and toil of children. Volume VI: An Economic Consideration of Child Labour: US Department of Labour; Bureau of International Labour Affairs: 2000, Washington DC.

28. UNICEF, 1997. The State of the World's Children 1997. UNICEF, Oxford and New York: Oxford University Press for UNICEF.

29. UNICEF, 1998. The State of the World's Children 1999. UNICEF, New York.

30. UNICEF, 1999. Child Domestic Work; Innocenti Digest 5. UNICEF Publication, Florence.

31. UNICEF, 2001. Child Labour in the West Bank and Gaza Strip: http://www.pna/mol/ice/papers/unicef.html

32. Union-Network, 1999. Initiatives by European Commerce to Combat Child Labour. Final Report to Euro Commerce and Euro-FIET.

33. Weiner, M. 1990. The child and the state in India: Child labour and education policy in comparative perspective; As cited in ILO (2004:112)

34. WCL, 2001. Child Labour: World Confederation on Labour: http://www.cmt-wcl.org/en/pubs/childl.htm. 